(2) Open Access Full Text Article

ORIGINAL RESEARCH

\title{
A novel long-sustaining system of apatinib for long-term inhibition of the proliferation of hepatocellular carcinoma cells
}

This article was published in the following Dove Press journal:

OncoTargets and Therapy

\section{Yanli Wang' \\ Zigui Tang ${ }^{1,2}$}

'Recruitment and Employment Office, Henan Medical College, Zhengzhou 45 II9I, Henan Province, People's Republic of China; ${ }^{2}$ Department of Pharmacy, Henan Medical College, Zhengzhou 45II9I, Henan Province, People's Republic of China
Correspondence: Yanli Wang Recruitment and Employment Office, Henan Medical College, 8 Shuanghu Road, Xinzheng District, Zhengzhou 45II9I, Henan Province, People's Republic of China

Tel/fax +86 37। 6257 68I I

Emailwylhnyz@l63.com
Background: Apatinib is a newly approved antitumor drug (molecular targeted agent/small molecular kinase inhibitor) for advanced hepatocellular carcinoma (HCC) treatment. However, current oral administration of apatinib could induce the even distribution of drugs in the body and cause the concentration of apatinib in the HCC location to be limited or insufficient. Therefore, it is urgent to develop novel formulations of apatinib to improve its efficiency.

Materials and methods: Apatinib was prepared to form a stable and even dispersion with cyclodextrin (a clathrate complex/inclusion complex named Apa-Cyc). A temperature-sensitive phase-change hydrogel of apatinib (named Apa-Gel) was prepared using apatinib-cyclodextrin and poloxamer 407. Apa-Gel was injected into HCC tissues in nude mice to examine the longterm antitumor effect.

Results: Apa-Gel can transform from liquid to hydrogel at near body temperature and maintain slow release of apatinib in HCC tumor tissues. When injected subcutaneously, one-time administration of Apa-Gel has a long-acting antitumor effect on the subcutaneous growth or epithelial-mesenchymal transition process of HCC cells.

Conclusion: This novel slow-releasing system allows apatinib to be released effectively on the long term and facilitates tissue attachment, thereby preserving the efficiency of apatinib over the long term.

Keywords: advanced hepatocellular carcinoma, apatinib-cyclodextrin inclusion complex, long sustaining and long acting

\section{Introduction}

Oral administration of molecular targeted agents (multitarget protein kinase inhibitors) continues to be the primary choice for advanced hepatocellular carcinoma (HCC) chemotherapeutic treatment (antitumor agent treatment). ${ }^{1-5}$ Sorafenib (BAY 43-9006) was the first approved molecular targeted agent and remains one of the foremost choices for advanced HCC treatment. ${ }^{6,7}$ Recently, some other molecular targeted agents, eg, apatinib or regorafenib (BAY 73-4506), were approved for the treatment of advanced HCC ${ }^{8-10}$ Application of molecular targeted agents could prolong the survival and improve the life quality of patients suffering from advanced HCC ${ }^{8-10}$ However, current oral administration of these drugs is still not satisfactory. Oral administration of these drugs could induce the even distribution of drugs in the entire body and cause the concentration of drugs in the HCC location to be limited or insufficient. Moreover, high daily doses (over $800 \mathrm{mg}$ ) result in a range of side effects and heavy financial burden. ${ }^{11}$ Our aim is to develop novel approaches for increasing the efficacy and safety of molecular targeted agents. 
Apatinib is a newly approved antitumor drug (molecular targeted agent/small molecular kinase inhibitor) for advanced HCC treatment. ${ }^{12}$ As a result of the structure of apatinib, it is hydrophilic in nature but not easily soluble. The current strategy is to prepare apatinib as apatinib mesylate $\left(\mathrm{AiTan}^{\circledR}\right.$, apatinib mesylate tablets). ${ }^{13}$ Although preparation of apatinib as apatinib mesylate tablets could possibly improve the solubility of apatinib, ionized apatinib (positive ion) may not improve transmembrane conductance in the human gastrointestinal system after oral administration. Therefore, it is valuable to develop novel pharmaceutical formulations for apatinib. In this work, apatinib was prepared to achieve a stable and even dispersion with cyclodextrin. A temperature-sensitive phase-change hydrogel (Apa-Gel) was prepared using apatinib-cyclodextrin and poloxamer 407 . Apa-Gel was injected into HCC tissues in nude mice.

\section{Materials and methods Cell culture and agents}

MHCC97-H cells (a highly aggressive HCC cell line) were purchased from Type Culture Collection of the Chinese Academy of Sciences (Shanghai, People's Republic of China), an organization possessing typical biological samples of the Chinese government. The protocol, methods, and usage of cell line in cell-based experiments were approved by the Ethics Committee, Henan Medical College. MHCC97-H cells were cultured in DMEM (Thermo Fisher Scientific Corporation, Waltham, MA, USA) with $10 \%$ FBS (Thermo Fisher Scientific Corporation) in $5 \% \mathrm{CO}_{2}$ at $37^{\circ} \mathrm{C}$. Apatinib mesylate (Cat. No S2221) was purchased from Selleck Corporation (Houston, TX, USA). Cyclodextrin was purchased from Sinopharm Chemical Reagent Beijing Corporation (Beijing, People's Republic of China).

\section{Preparation of apatinib formulations}

Apatinib mesylate was first prepared into apatinib. For the apatinib suspension preparation (named Control), $20 \mathrm{mg}$ of apatinib was simply mixed with $10 \mathrm{~mL}$ of double-distilled $\mathrm{H}_{2} \mathrm{O}\left(\mathrm{ddH}_{2} \mathrm{O}\right)$. For the apatinib solution preparation, $20 \mathrm{mg}$ of apatinib was dissolved in a solution of $100 \mu \mathrm{L}$ dimethyl sulfoxide, $200 \mu \mathrm{L}$ polyethylene glycol 400 (PEG 400), and $200 \mu \mathrm{L}$ Tween 80 . Next, the solutions were carefully and slowly diluted by PBS to a total volume of $10 \mathrm{~mL}$, accompanied with ultrasonic or churning treatment. The apatinib concentration in the diluted solution (named Apa-Sol) was $\sim 2 \mathrm{mg} / \mathrm{mL}$. For the apatinib-cyclodextrin clathrate complex/ inclusion complex preparation, apatinib and cyclodextrin were mixed to form an apatinib-cyclodextrin inclusion complex (named Apa-Cyc), following the methods provided by Giglio et al and Kim et al. ${ }^{14,15}$ Next, these formulations were scanned by a multifunctional microplate reader to examine the OD values under a series of wavelengths. For temperature-sensitive phase-change hydrogel of apatinib preparation, poloxamer 407 (FREDA Corporation, Jinan City, People's Republic of China) was added to the apatinibcyclodextrin inclusion complex formulation (Apa-Cyc). Moreover, these formulations were extracted with acetonitrile (ACN), and the apatinib in each formulation was examined by liquid chromatography mass spectrometry/mass spectrometry (LC-MS/MS) methods as described by Feng et al, Feng et al, and Xie et al. ${ }^{16-18}$

\section{Releasing or clearance of apatinib}

All animal experiment protocols were approved by the Institutional Animal Care and Use Committee of Henan Medical College. All animal studies were carried out in accordance with the UK Animals (Scientific Procedures) Act of 1986 and associated guidelines. MHCC97-H cells were cultured and seeded into nude mice to prepare the subcutaneous tumor model. When the tumor volumes reached 1,200-1,500 $\mathrm{mm}^{3}$, the apatinib formulations (Solvent Control, Apa-Cyc, ApaGel, and Apa-Sol) were injected into subcutaneous tumors formed by MHCC97-H cells. Total volumes of formulations were $50 \mu \mathrm{L}$ for each tumor, and formulations were administered once by intratumor injection. At the indicated time points, mice were harvested, and tumor tissues were collected. Collected tumor tissues were weighed and lysated, and apatinib sustaining in tumor tissues was extracted with ACN for LC-MS/MS examination. The LC-MS/MS experiments were performed, and the sustaining curves of apatinib in HCC tumor tissues were obtained through calculations following the methods provided by Xie et al, Feng et al, Li et al, and $\mathrm{Wu}$ et al. ${ }^{18-21}$

\section{In vivo antitumor effects of apatinib}

MHCC97-H cells were cultured and injected into nude mice $\left(5 \times 10^{6}\right.$ cells per animal) to form subcutaneous tumor models..$^{22,23}$ To examine the antitumor effect of oral administration of apatinib mesylate suspension to mimic the apatinib clinical application or tail vein injection of Apa-Cyc prepared in this present work, nude mice 4-6 weeks of age were purchased from Si-Bei-Fu Corporation (Beijing, People's Republic of China). Four to five days after MHCC97-H cells were injected into nude mice, the mice received oral administration of the indicated dose of apatinib mesylate to mimic 
the clinical application of apatinib or tail vein injection of the indicated dose of Apa-Cyc every 2 days. After 25 days of treatment (12 treatments), tumors were harvested. Tumor weight was measured by precision balances, and tumor volumes were measured as length $\times$ width $\times$ width $/ 2$.

Next, to examine the long-acting antitumor effect of Apa-Gel on HCC cells' subcutaneous growth, MHCC97-H cells were injected into nude mice to form subcutaneous tumors. After 1-2 weeks of growth, when tumors reached $1,000-1,200 \mathrm{~mm}^{3}$ volume, mice were randomly divided into four groups as follows: 1) solvent control group (mice with intratumors injected with $50 \mu \mathrm{L}$ solvent control); 2) mice with intratumors injected with $50 \mu \mathrm{L}$ Apa-Sol; 3) mice with intratumors injected with $50 \mu \mathrm{L}$ Apa-Cyc; and 4) mice with intratumors injected with $50 \mu \mathrm{L}$ Apa-Gel. After 14-20 days of growth, tumors were harvested. Tumor weight was measured by precision balances and tumor volumes were measured as length $\times$ width $\times$ width/2.24,25

\section{Quantitative polymerase chain reactions} MHCC97-H cells were injected into nude mice to form subcutaneous tumors. After 1-2 weeks of growth, when tumors reached $1,000-1,200 \mathrm{~mm}^{3}$ volume, the mice were randomly divided into four groups as follows: 1) untreated group; 2) mice with intratumors injected with Apa-Sol; 3) mice with intratumors injected with Apa-Cyc; and 4) mice with intratumors injected with Apa-Gel. After 14-20 days growth, tumors were harvested, and total RNA samples were extracted with the PARISTM Kit (Applied Biosystems, Foster City, CA, USA) and reverse transcribed to cDNA with a Multiscribe ${ }^{\mathrm{TM}}$ Reverse Transcriptase Kit (Applied Biosystems) according to the manufacturer's instructions for quantitative polymerase chain reactions (qPCRs). The mRNA levels of E-cadherin, $\mathrm{N}$-cadherin, and vimentin were examined by qPCR, referring to the methods described by Kang et al. ${ }^{26}$ The sequences of the primers used are presented in Table 1.

Table I The primers used in this work

\begin{tabular}{l|l}
\hline Targets & Primer sequence (5'-3') \\
\hline E-cadherin & $\begin{array}{l}\text { Forward: 5'-AAGGCACGCCTGTCGAAGCA-3' } \\
\text { Reverse: 5'-ACGTTGTCCCGGGTGTCATCCT-3' }\end{array}$ \\
\hline N-cadherin & $\begin{array}{l}\text { Forward: 5'-TGCGCGTGAAGGTTTGCCAGT-3' } \\
\text { Reverse: 5'-TGGCGTTCTTTATCCCGGCGT-3' }\end{array}$ \\
\hline Vimentin & $\begin{array}{l}\text { Forward: 5'-ACCGCACACAGCAAGGCGAT-3' } \\
\text { Reverse: 5'-CGATTGAGGGCTCCTAGCGGTT-3' }\end{array}$ \\
\hline$\beta$-actin & $\begin{array}{l}\text { Forward: 5'-ACCGCACACAGCAAGGCGAT-3' } \\
\text { Reverse: 5'-CGATTGAGGGCTCCTAGCGGTT-3' }\end{array}$ \\
\hline
\end{tabular}

\section{Statistical analysis}

Statistical analysis was carried out using Bonferroni's correction with or without two-way analysis of variance using SPSS Statistics software (IBM Corporation, Armonk, NY, USA). The half-life ( $t_{1 / 2}$ value) of apatinib in MHCC97-H was calculated with Origin software (Version No 6.1; OriginLab Corporation, Northampton, MA, USA). A $P$-value $<0.05$ was considered statistically significant between groups.

\section{Results Preparation of apatinib formulations}

To reveal the characteristics of the apatinib formulations, the samples were examined by either multifunctional microplate reader or LC-MS/MS methods. As shown in Figure 1A, apatinib simply mixed in $\mathrm{ddH}_{2} \mathrm{O}$ was a suspension containing tiny drug particles and had much higher absorbance value measured under a series of wavelengths than the Solvent Control group, Control group, Apa-Sol group, or Apa-Cyc group. Next, the apatinib suspension (Control group) was filtered with a $0.22 \mu \mathrm{m}$ pore size filter to extract undissolved apatinib particles and used as the control. The concentrations of apatinib in the formulations were determined. As shown in Table 2, the concentrations of apatinib in Apa-Sol and ApaCyc were $1.93 \pm 0.16$ and $1.99 \pm 0.08 \mathrm{mg} / \mathrm{mL}$, respectively, and after multiple filtrations $(0.22 \mu \mathrm{m}$ aperture $)$, apatinib sustaining in the apatinib suspension was found to be rare $(0.03 \pm 0.02 \mathrm{mg} / \mathrm{mL})$. The results identifying apatinib in formulations from LC-MS/MS are shown in Figure 1B-F. Therefore, we successfully prepared the formulations of apatinib and determined the features and apatinib concentrations in the formulations.

\section{The antitumor effect of apatinib formulations}

To reveal whether Apa-Cyc could be used in HCC treatment, MHCC97-H cells were seeded into nude mice to form subcutaneous tumors. Mice received apatinib treatment by 1) oral administration of apatinib mesylate to mimic the clinical application of apatinib or 2) injection of Apa-Cyc through the tail vein. Results are shown in Figure 2. Oral administration of a $2 \mathrm{mg} / \mathrm{kg}$ dose of apatinib significantly reduced the tumor volumes or tumor weights of MHCC97-H cells. The antitumor effects of 0.5 and $1.0 \mathrm{mg} / \mathrm{kg}$ doses of apatinib were weaker than that of the $2 \mathrm{mg} / \mathrm{kg}$ dose (Figure 2). Oral administration of a $0.2 \mathrm{mg} / \mathrm{kg}$ dose of apatinib did not significantly inhibit the subcutaneous growth of MHCC97-H cells in nude mice (Figure 2). Injection of 0.5, 0.2 , and $0.1 \mathrm{mg} / \mathrm{kg}$ doses of Apa-Cyc through the tail vein inhibited the subcutaneous 
A

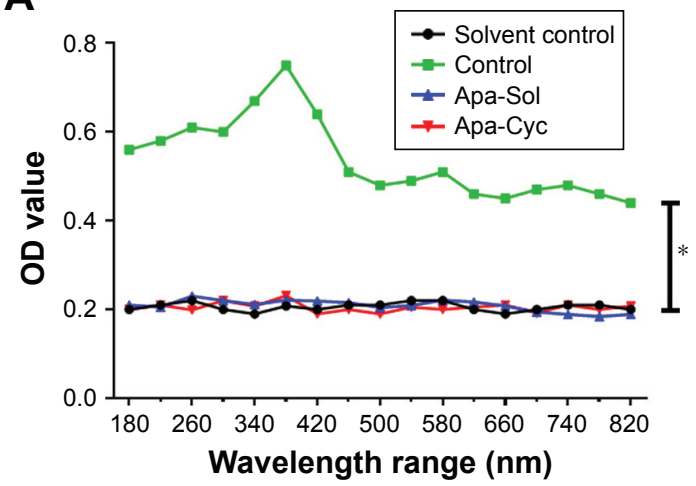

C
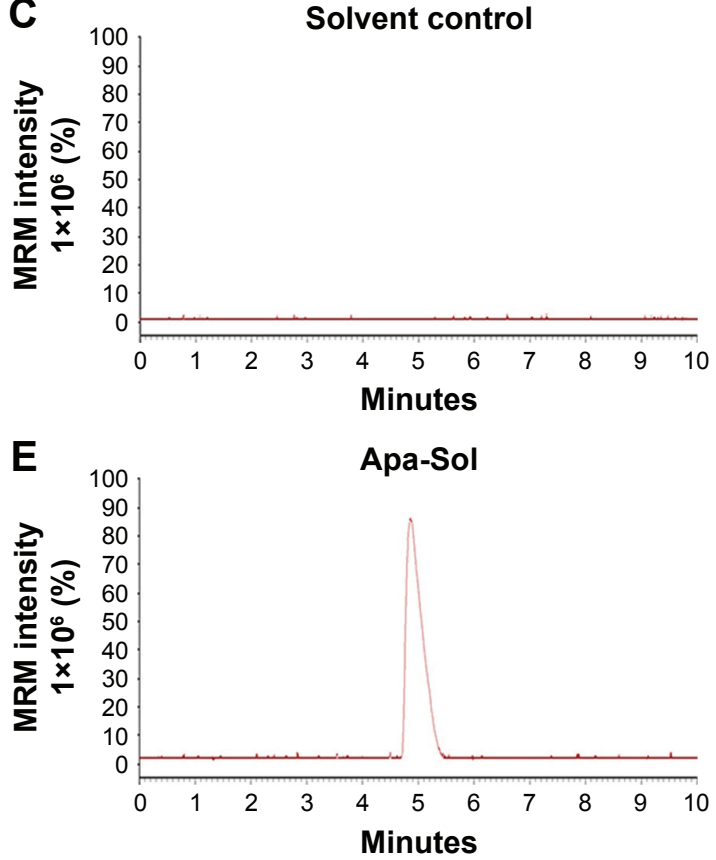

B

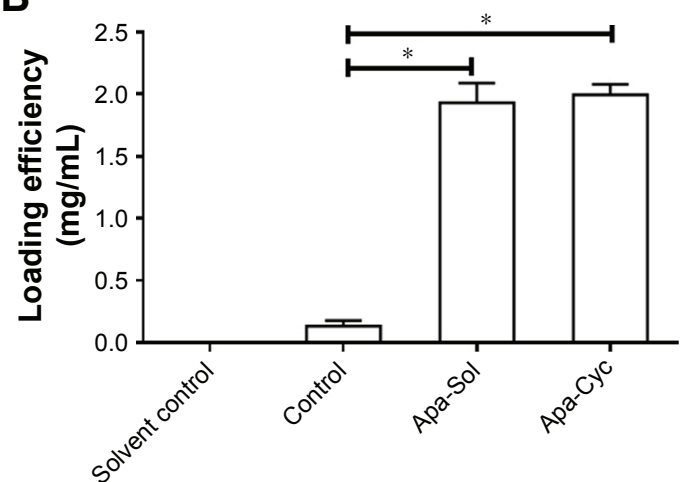

D

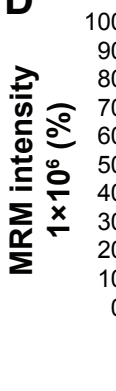

Control

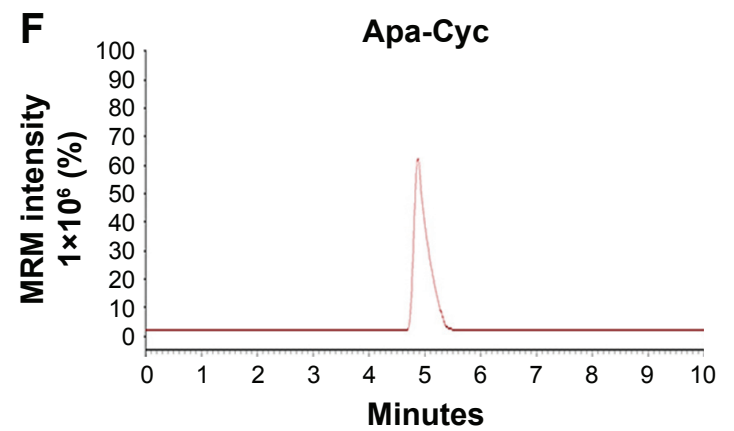

Figure I Preparation of apatinib formulations.

Notes: Apatinib was I) simply mixed with $\mathrm{ddH}_{2} \mathrm{O}$ to form an apatinib suspension (named Control); 2) dissolved in organic solvents and diluted in dd $\mathrm{H}_{2} \mathrm{O}$ to form an apatinib solution (named Apa-Sol); and 3) mixed with cyclodextrin to form an apatinib-cyclodextrin inclusion complex (named Apa-Cyc). (A) Apatinib formulations were scanned with a microplate reader to obtain the OD values of apatinib formulations (Control, Apa-Sol, and Apa-Cyc) measured under a series of wavelengths. Cyclodextrin solution in $\mathrm{ddH}_{2} \mathrm{O}$ was used as a solvent control. (B) Apatinib suspension was filtered with a $0.22 \mu \mathrm{m}$ pore diameter filter membrane. Apatinib formulations (Control, Apa-Sol, and Apa-Cyc) were extracted by ACN for LC-MS/MS examination. (C-F) The typical photographs of Solvent Control (C), Control (apatinib suspension) (D), Apa-Sol (E), and Apa-Cyc (F) by LC-MS/MS. $* P<0.05$.

Abbreviations: ACN, acetonitrile; Apa-Cyc, apatinib-cyclodextrin inclusion complex; Apa-Sol, apatinib solution; ddH $\mathrm{O}_{2} \mathrm{O}$, double-distilled $\mathrm{H}_{2} \mathrm{O}$; LC-MS/MS, liquid chromatography mass spectrometry/mass spectrometry; MRM, multi reaction monitoring.

growth of MHCC97-H cells in nude mice (Figure 2). The antitumor effects of 0.1 and $0.2 \mathrm{mg} / \mathrm{kg}$ doses of Apa-Cyc were much lower than those of the $0.5 \mathrm{mg} / \mathrm{kg}$ dose of ApaCyc, and injection of a $0.05 \mathrm{mg} / \mathrm{kg}$ dose of Apa-Cyc did not

Table 2 The loading efficiency of apatinib formulations

\begin{tabular}{l|l}
\hline Groups & Loading efficiency $(\mathrm{mg} / \mathrm{mL})$ \\
\hline Solvent control & - \\
Control & $0.03 \pm 0.02$ \\
Apa-Sol & $1.93 \pm 0.16$ \\
Apa-Cyc & $1.99 \pm 0.08$ \\
\hline
\end{tabular}

Notes: Data are presented as mean \pm SD.

Abbreviations: Apa-Cyc, apatinib-cyclodextrin inclusion complex; Apa-Sol, apatinib solution; Control, apatinib suspension. significantly inhibit the subcutaneous growth of MHCC97-H cells in nude mice (Figure 2). Moreover, the antitumor effect of the injection of a $0.5 \mathrm{mg} / \mathrm{kg}$ dose of Apa-Cyc was more effective than the oral administration of a $2 \mathrm{mg} / \mathrm{kg}$ dose of apatinib. The inhibition rate of the oral administration of a $2 \mathrm{mg} / \mathrm{kg}$ dose of apatinib on the subcutaneous growth of MHCC97-H cells in nude mice was $64.19 \% \pm 7.22 \%$, whereas the inhibition rate of the injection of a $0.5 \mathrm{mg} / \mathrm{kg}$ dose of ApaCyc on subcutaneous growth of MHCC97-H cells in nude mice was $87.93 \% \pm 3.54 \%$. Therefore, the formulation of ApaCyc not only achieved injective administration of apatinib but also improved the efficiency of apatinib treatment. Also, the 
A
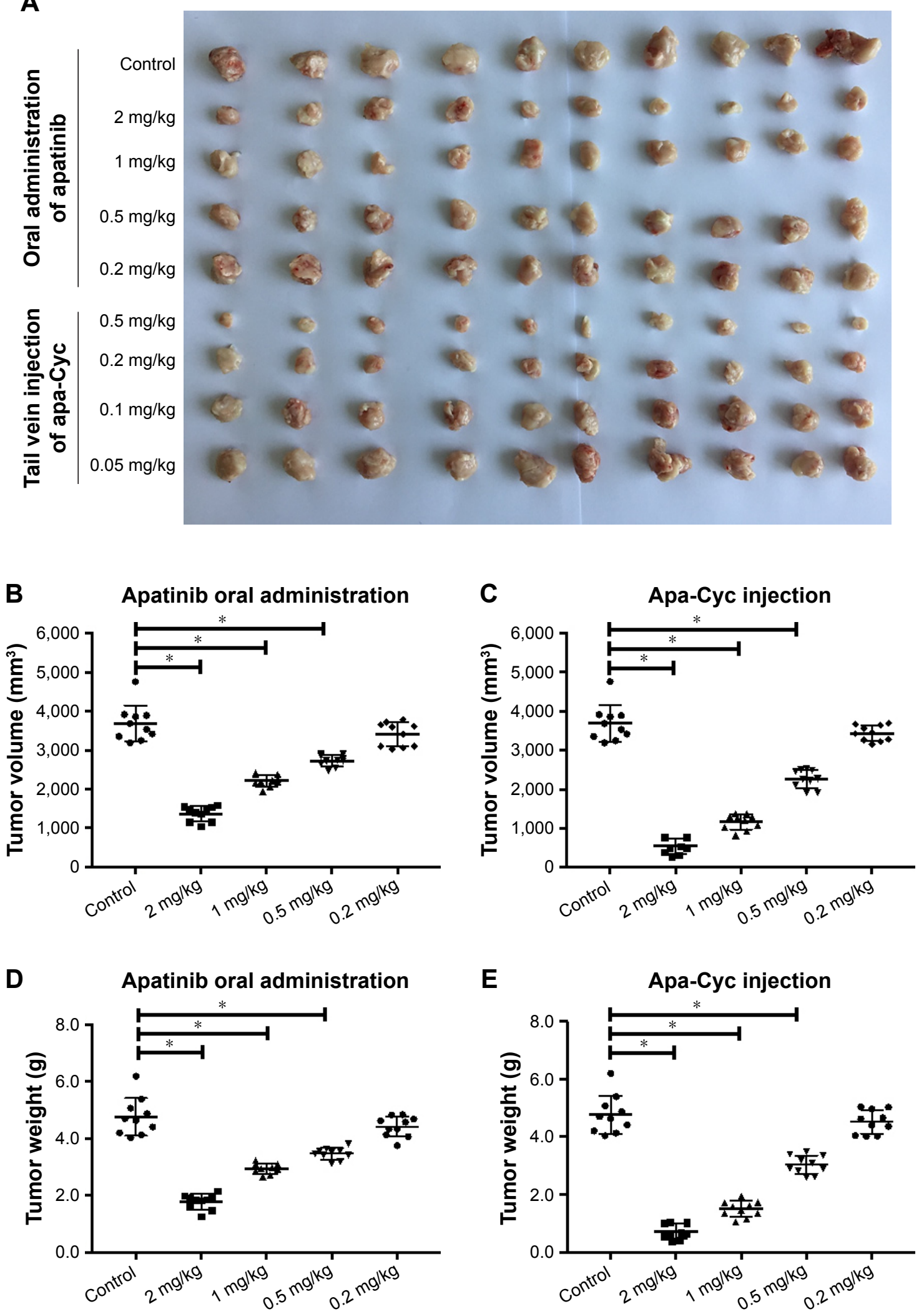

Figure 2 Antitumor effect of apatinib formulations on the subcutaneous growth of MHCC97-H cells.

Notes: MHCC97-H cells were injected into nude mice to form subcutaneous tumors. The mice that received solvent control PBS was the control group. The indicated doses of apatinib were orally administered or injected via the tail vein with an indicated dose of Apa-Cyc to the mice. The results are shown as (A) photographs of tumors, (B) tumor volumes of nude mice receiving orally administered apatinib, (C) tumor volumes of nude mice receiving tail vein-injected Apa-Cyc, (D) tumor weights of nude mice receiving orally administered apatinib, and $(\mathbf{E})$ tumor weights of nude mice receiving tail vein-injected Apa-Cyc. $* P<0.05$ vs apatinib oral administration group with control group (untreated group); $* P<0.05$ vs apatinib injection group with control group (untreated group).

Abbreviation: Apa-Cyc, apatinib-cyclodextrin inclusion complex. 
Table 3 Phase-transition temperature of Apa-Gel containing different poloxamer 407 concentrations

\begin{tabular}{l|l}
\hline Poloxamer $407(\%)$ & $\begin{array}{l}\text { Phase-transition } \\
\text { temperature }\left(\boldsymbol{t}_{1 / 2} ;{ }^{\circ} \mathbf{C}\right)\end{array}$ \\
\hline 5.0 & - \\
7.5 & $41.38 \pm 0.18$ \\
10.0 & $39.21 \pm 0.44$ \\
12.5 & $37.05 \pm 0.22$ \\
15.0 & $32.11 \pm 0.27$ \\
17.5 & $25.50 \pm 0.33$ \\
20.0 & $19.83 \pm 0.54$ \\
\hline
\end{tabular}

Note: Data are presented as \% or mean \pm SD.

injection of a smaller concentration of Apa-Cyc achieved a therapeutic effect similar to that of the oral administration of a much higher dose of the apatinib.

\section{Intratumor injection of Apa-Gel and the long-term sustaining of apatinib in $\mathrm{HCC}$ tumor tissues}

As mentioned above, we successfully prepared a cyclodextrin inclusion complex of apatinib, which enabled to inject apatinib far more effectively for treating advanced HCC. Next, a temperature-sensitive phase-change hydrogel of apatinib (named Apa-Gel) was prepared by using apatinib-cyclodextrin and poloxamer 407. As shown in Table 3, Apa-Gel achieved phase-change features and transformed from liquid to hydrogel. The phase-transition temperature of Apa-gel containing
$7.5 \%, 10 \%, 12.5 \%, 15 \%, 17.5 \%$, and $20 \%$ poloxamer 407 was $41.38^{\circ} \mathrm{C} \pm 0.18^{\circ} \mathrm{C}, 39.21^{\circ} \mathrm{C} \pm 0.44^{\circ} \mathrm{C}, 37.05^{\circ} \mathrm{C} \pm 0.22^{\circ} \mathrm{C}$, $32.11^{\circ} \mathrm{C} \pm 0.27^{\circ} \mathrm{C}, 25.50^{\circ} \mathrm{C} \pm 0.33^{\circ} \mathrm{C}$, and $19.83^{\circ} \mathrm{C} \pm 0.54^{\circ} \mathrm{C}$, respectively. Therefore, the phase-transition temperature of Apa-Gel which contains $12.5 \%$ poloxamer 407 was nearest to body temperature $\left(37.05^{\circ} \mathrm{C} \pm 0.22^{\circ} \mathrm{C}\right)$, so we chose $12.5 \%$ poloxamer 407 for further steps of the experiment.

To identify whether Apa-Gel could achieve the longterm sustaining of apatinib, the in vitro release of Apa-Gel was determined by LC-MS/MS experiments. As shown in Figure 3, Apa-Gel achieved the slow-releasing of apatinib. Apatinib could sustain in Apa-Gel for more than 400 hours. The $t_{1 / 2}$ value of apatinib releasing from Apa-Gel was 164.57 \pm 7.82 hours. Therefore, the formulation of Apa-Gel achieved long-term releasing of apatinib.

\section{Intratumor injection of Apa-Gel and the long-acting antitumor effect of apatinib}

To further examine the long-sustaining feature of Apa-Gel, MHCC97-H cells were seeded into nude mice to form subcutaneous tumors, and apatinib formulations were injected into the subcutaneous tumors. Next, tumor tissues were harvested at indicated time points for LC-MS/MS analysis to examine the sustaining of apatinib in tumor tissues. As shown in Figure 4 and Table 4, after Apa-Sol and Apa-Cyc injections, apatinib was almost completely cleared from the tumor
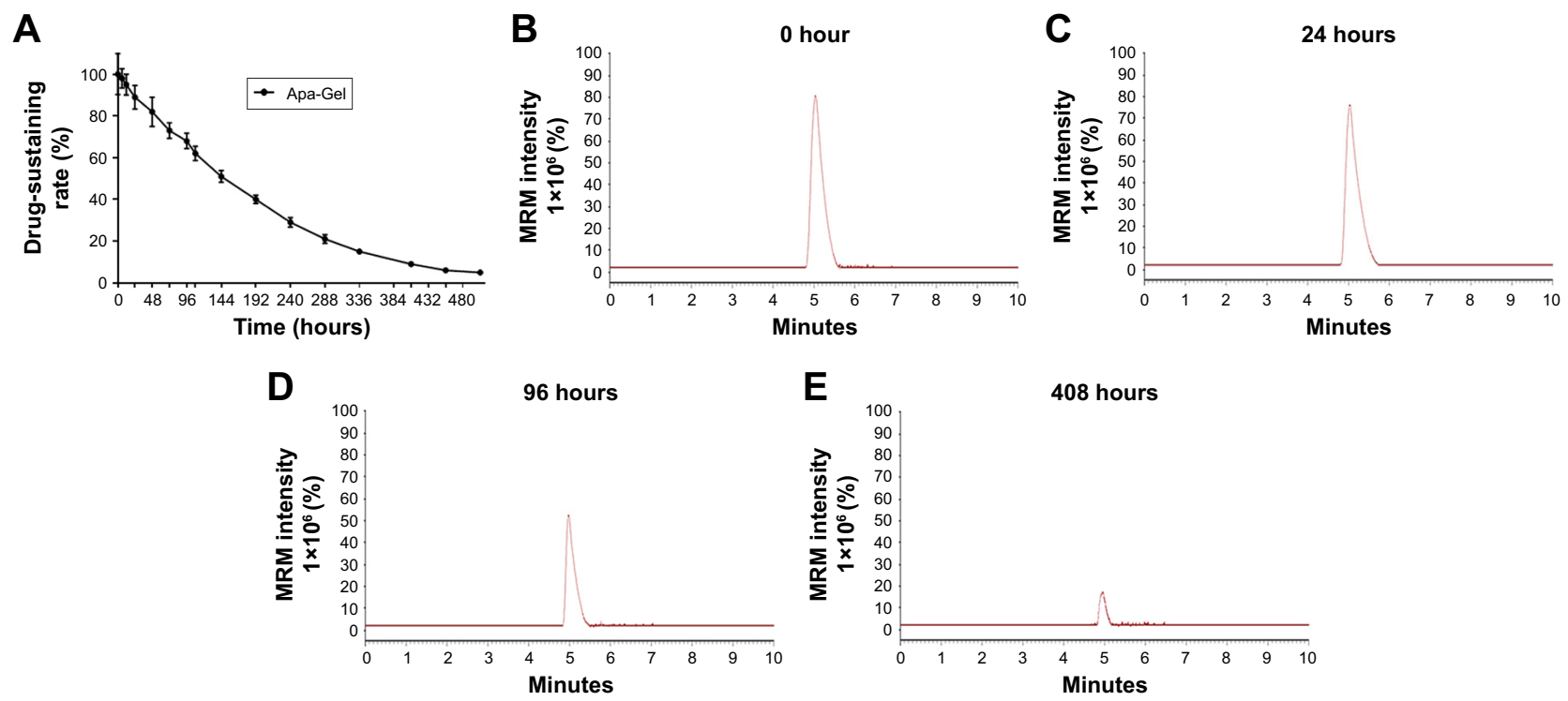

Figure 3 In vitro release of Apa-Gel.

Notes: Apa-Cyc was prepared to form a temperature-sensitive phase-change hydrogel (named Apa-Gel). Apa-Gel was incubated in ddH $\mathrm{O}_{2} \mathrm{O}$ at $37^{\circ} \mathrm{C}$. $\mathrm{The}^{\mathrm{ddd}} \mathrm{O}_{2} \mathrm{O}$ was collected at the indicated time points for LC-MS/MS experiments. (A) Results are shown as the drug-sustaining curve of Apa-Gel. (B-E) The typical photographs of Apa-Gel at (B) 0-hour time point, (C) 24-hour time point, (D) 96-hour time point, and (E) 408-hour time point.

Abbreviations: $\mathrm{ACN}$, acetonitrile; Apa-Gel, a temperature-sensitive phase-change hydrogel of apatinib; ddH $\mathrm{H}_{2} \mathrm{O}$, double-distilled $\mathrm{H}_{2} \mathrm{O}$; $\mathrm{LC}^{-M S / M S}$, liquid chromatograph mass spectrometry/mass spectrometry; MRM, multi reaction monitoring. 
tissues at 48 hours. The $t_{1 / 2}$ values of apatinib in the Apa-Sol and Apa-Cyc groups were $16.55 \pm 1.66$ and $18.65 \pm 2.07$ hours, respectively. Compared to Apa-Sol and Apa-Cyc, injections of Apa-Gel achieved long-term sustaining in tumor tissues $\left(t_{1 / 2}\right.$ value was $99.16 \pm 7.67$ hours), and apatinib could still be detected in tumor tissues at the 408-hour time point.

To further examine the potential application of Apa-Gel in HCC treatment, we examined whether Apa-Gel could exert a long-term antitumor effect on HCC tissues. Poloxamer hydrogel itself did not inhibit the subcutaneous growth of MHCC-97H cells in nude mice (Figure S1). Results are
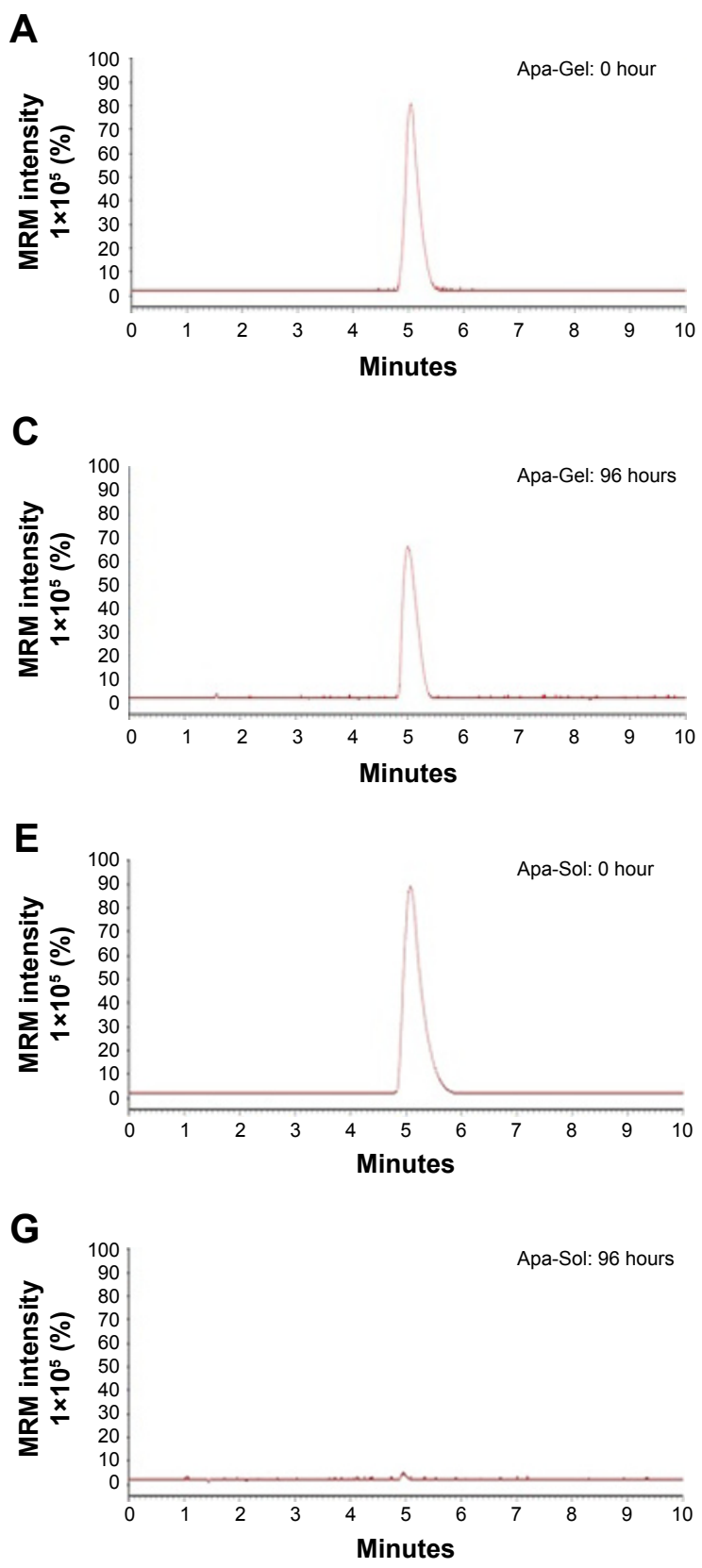

shown in Figure 5. One intratumor injection of Apa-Gel, but not Apa-Sol or Apa-Cyc, inhibited the subcutaneous growth of MHCC97-H cells in nude mice compared with that in the untreated control group. Moreover, to further examine the antitumor effect of Apa-Gel on MHCC97-H cells, qPCR experiments were performed. As shown in Figure 6, one administration of Apa-Gel, but not Apa-Sol or Apa-Cyc, significantly enhanced the mRNA level of E-cadherin, an epithelial indicator (Figure 6A) and decreased the mRNA level of $\mathrm{N}$-cadherin and vimentin, both of which are mesenchymal indicators (Figure 6B and C). Therefore, intratumor

B

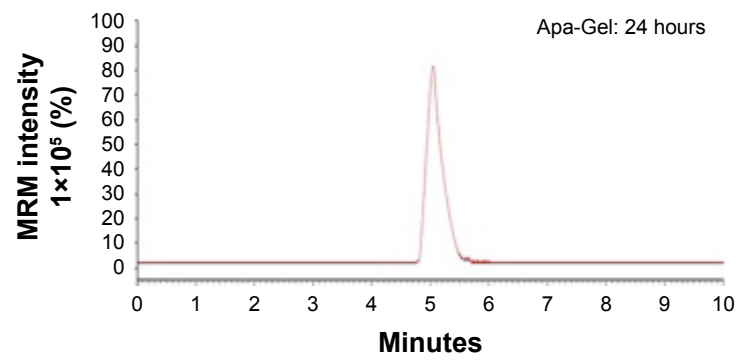

D
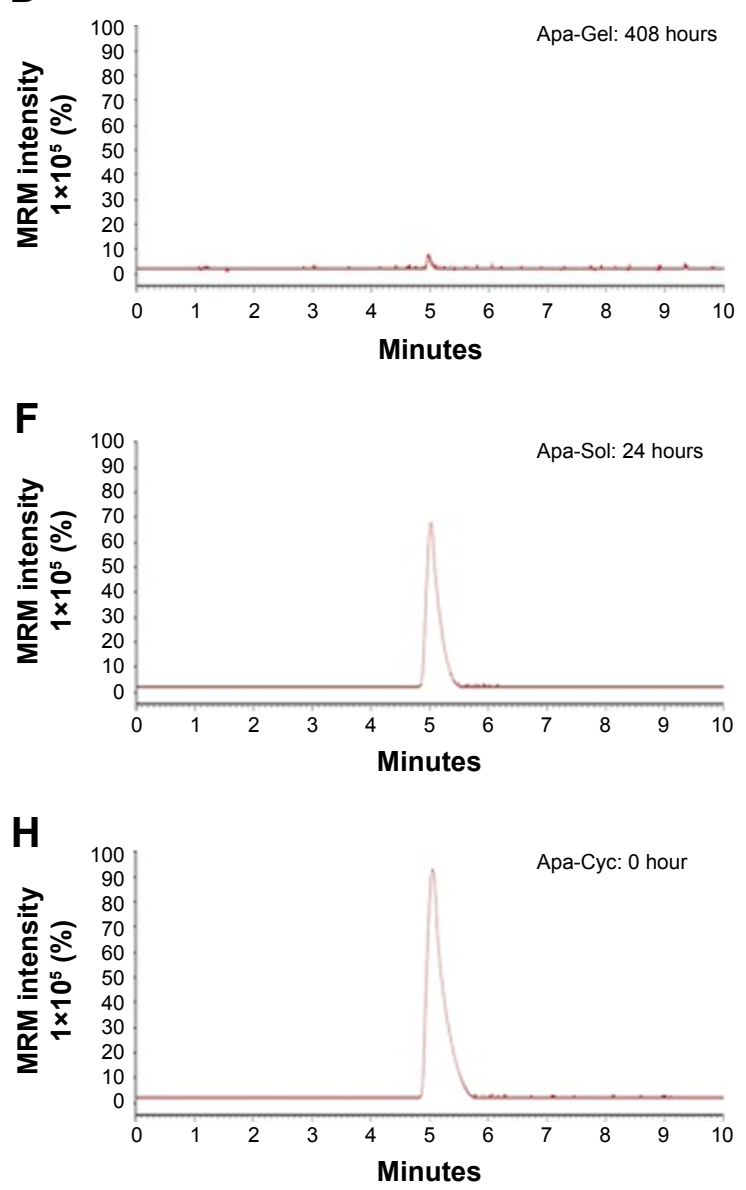

Figure 4 (Continued) 

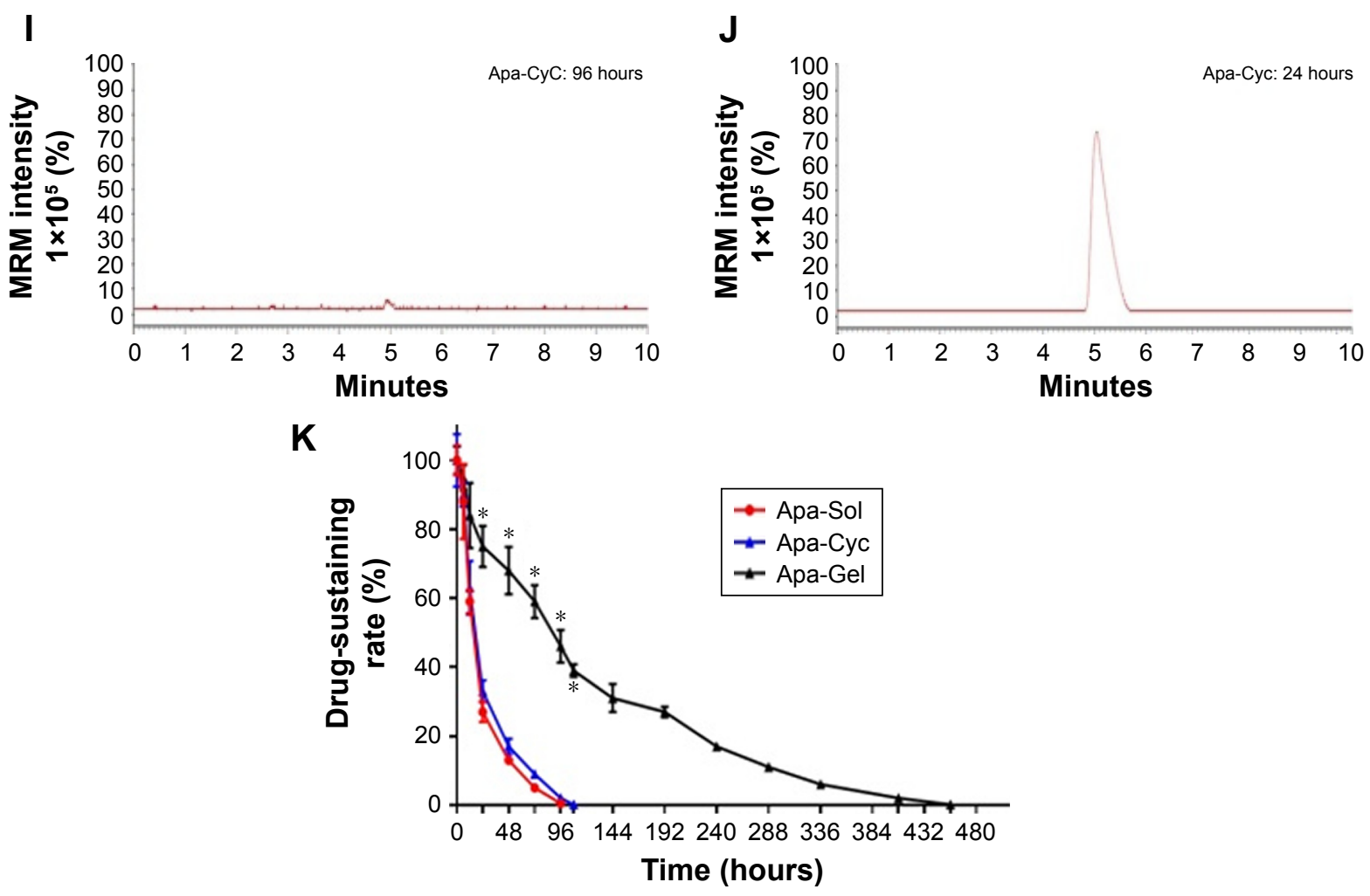

Figure 4 In vivo release of apatinib formulations in $\mathrm{HCC}$ tumor tissues.

Notes: Apa-Gel, Apa-Sol, and Apa-Cyc were injected into subcutaneous tumor tissues formed by MHCC97-H cells. At the indicated time points, tumor tissues were harvested and apatinib sustaining in tumor tissues was extracted by ACN for LC-MS/MS examination. (A-D) Apatinib sustaining in HCC subcutaneous tumor tissues injected with Apa-Gel formed by MHCC97-H cells was examined at (A) 0-hour time point, (B) 24-hour time point, (C) 96-hour time point, and (D) 408-hour time point with LCMS/MS. (E-G) Apatinib sustaining in HCC subcutaneous tumor tissues injected with Apa-Sol formed by MHCC97-H cells was examined at (E) 0-hour time point, (F) 24-hour time point, and (G) 96-hour time point with LC-MS/MS. (H-J) Apatinib sustaining in HCC subcutaneous tumor tissues injected with Apa-Cyc formed by MHCC97-H cells was examined at (H) 0-hour time point, (J) 24-hour time point, and (I) 96-hour time point with LC-MS/MS. (K) The sustaining curve of apatinib in subcutaneous tumor tissues formed by MHCC $97-\mathrm{H}$ cells is shown. $* P<0.05$ vs Apa-Gel group with Apa-Sol group; $* P<0.05$ vs Apa-Gel group with Apa-Cyc group.

Abbreviations: ACN, acetonitrile; Apa-Gel, a temperature-sensitive phase-change hydrogel of apatinib; Apa-Sol, apatinib solution; Apa-Cyc, apatinib-cyclodextrin inclusion complex; LC-MS/MS, liquid chromatography mass spectrometry/mass spectometry.

injection of Apa-Gel exerted a long-acting antitumor effect on HCC tumors and inhibited activation of the epithelialmesenchymal transition process of MHCC97-H cells in subcutaneous tumors.

\section{Discussion}

Despite many achievements in research related to advanced HCC treatment in recent years, there are limited options for drug treatment in advanced HCC. ${ }^{27}$ Sorafenib, the molecular targeted agent/small molecular protein kinase

Table 4 Half-life of apatinib in HCC tissues injected with apatinib formulations

\begin{tabular}{l|l}
\hline Apatinib formulations & $\begin{array}{l}\text { Half-life of apatinib in HCC } \\
\text { tissues }\left(\boldsymbol{t}_{1 / 2} \text { value; hours) }\right.\end{array}$ \\
\hline Apa-Sol & $16.55 \pm 1.66$ \\
Apa-Cyc & $18.65 \pm 2.07$ \\
Apa-Gel & $99.16 \pm 7.67$ \\
\hline
\end{tabular}

Notes: Data are presented as mean \pm SD.

Abbreviations: Apa-Cyc, apatinib-cyclodextrin inclusion complex; Apa-Sol, apatinib solution; HCC, hepatocellular carcinoma. inhibitor, remains the only first-line choice for advanced HCC treatment. ${ }^{28}$ Although sorafenib has been widely used to prolong survival and improve the daily life quality of patients with advanced HCC, there are many inadequacies: the antitumor efficiency of sorafenib in clinical application exhibits individual differences among patients, whereas sorafenib resistance often occurs during treatment in some patients who are initially sensitive to sorafenib. ${ }^{29,30}$ To solve these problems and achieve better therapeutic effects, a variety of new molecular targeted drugs, including regorafenib or apatinib, have been approved for clinical treatment of advanced HCC. Although these strategies, which rely on research and development of new drugs, could be innovative at the source and produce new drugs, there are still some problems: 1) the mechanism of drug resistance occurring during HCC treatment is not completely clear, and simply relying on the development new drugs is risky and costly and 2) sorafenib, apatinib, and regorafenib, which are all inhibitors of the VEGFR (vascular endothelial growth 
A

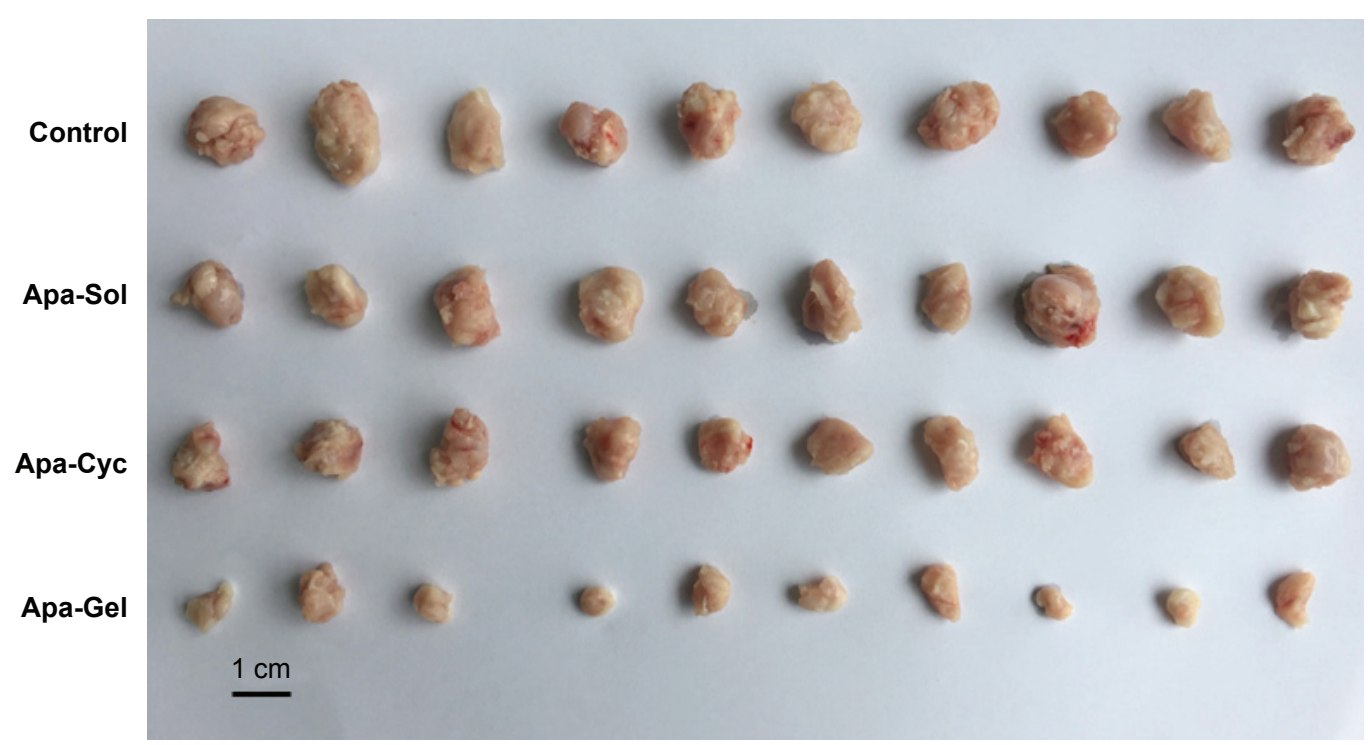

B

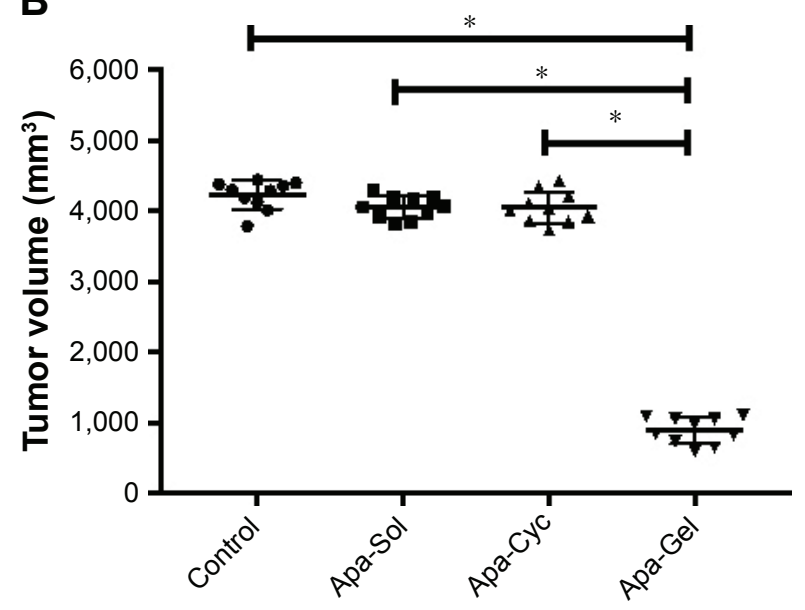

C

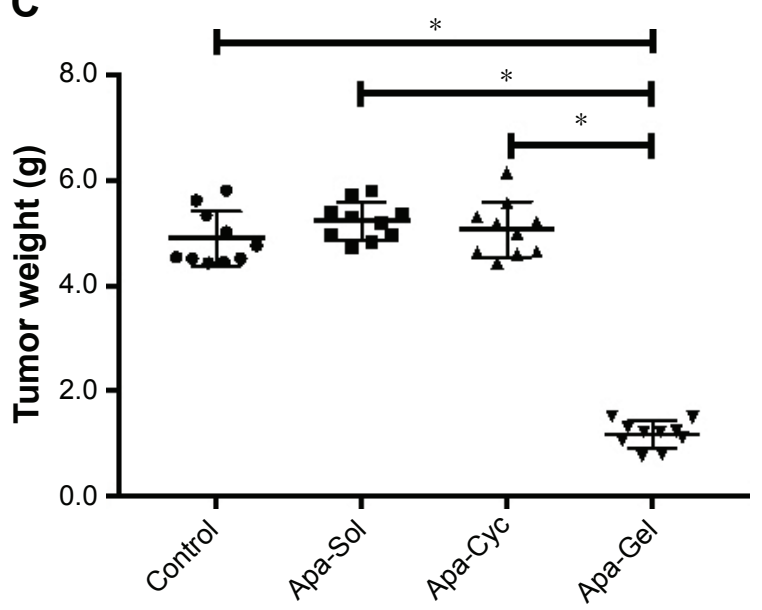

Figure 5 Long-acting antitumor effect of Apa-Gel formulations on the subcutaneous growth of MHCC97-H cells.

Notes: MHCC97-H cells were injected into nude mice to form subcutaneous tumors. The control group was the mice that received intratumor injection of solvent control. Mice were administered with one intratumor injection of Apa-Sol, Apa-Cyc, or Apa-Gel. The results are shown as (A) photographs of tumors, (B) tumor volumes, and (C) tumor weights. $* P<0.05$ vs Apa-Gel group with control group; $* P<0.05$ vs Apa-Gel group with Apa-Sol group; $* P<0.05$ vs Apa-Gel group with Apa-Cyc group. Abbreviations: Apa-Gel, a temperature-sensitive phase-change hydrogel of apatinib; Apa-Sol, apatinib solution; Apa-Cyc, apatinib-cyclodextrin inclusion complex.

factor receptor) and MAPK (mitogen-activated protein kinase) signaling pathways, have similar core and chemical properties, and it is difficult to make an epoch-making breakthrough. These problems result in higher demands on researchers.

Apatinib is a recently approved small molecular protein kinase inhibitor used in treating advanced HCC. Clinically, patients are prescribed oral AiTan ${ }^{\circledR}$, apatinib mesylate tablets, and there are no reports of other apatinib formulations for injections. ${ }^{13}$ Because the greatest proportion of HCC cases in People's Republic of China consists of HBV/HCV-related tumors, patients also often suffer from gastrointestinaldigestive tract dysfunctions caused by cirrhosis, ${ }^{31-34}$ which seriously affect the patient's absorption and bioavailability of orally administered apatinib. In addition, apatinib is chemically hydrophilic but has poor solubility. Although apatinib is often prepared to form a mesylate salt to improve its solubility, the ionized apatinib is not easily absorbed by the human intestinal tract. Therefore, exploring and establishing more effective strategies of administration and pharmaceutical formulation could help to improve the effectiveness of molecular targeted therapies. Cyclodextrin is a generic term for a series of linear oligosaccharides derived from cyclodextrin glucosyltransferase produced by Bacillus, which have a lumen that can form inclusion complexes and molecular assembly systems with many organic and 

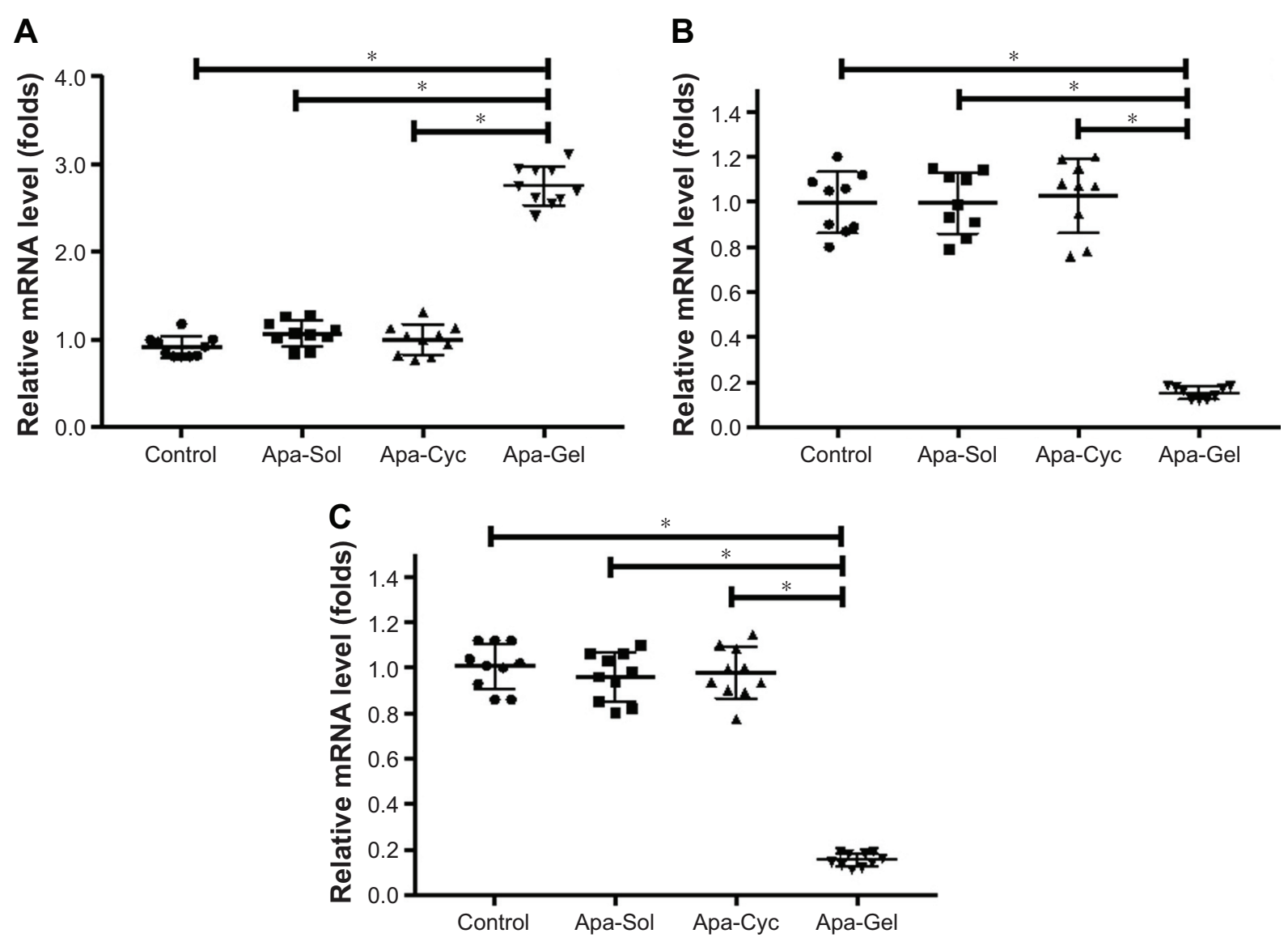

Figure 6 Long-acting antitumor effect of Apa-Gel formulations on the EMT process of MHCC97-H cells.

Notes: MHCC97-H cells were injected into nude mice to form subcutaneous tumors. The control group was the untreated group. Mice were administered with one intratumor injection of Apa-Sol, Apa-Cyc, or Apa-Gel. Tumors were harvested for qPCR experiments. The expression of (A) E-cadherin (an epithelial indicator), (B) $\mathrm{N}$-cadherin (a mesenchymal indicator), and (C) vimentin (a mesenchymal indicator) are shown. $* P<0.05$ vs Apa-Gel group with control group; $* P<0.05$ vs Apa-Gel group with Apa-Sol group; $* P<0.05$ vs Apa-Gel group with Apa-Cyc group.

Abbreviations: Apa-Cyc, apatinib-cyclodextrin inclusion complex; Apa-Gel, a temperature-sensitive phase-change hydrogel of apatinib; Apa-Sol, apatinib solution; EMT, epithelial-mesenchymal transition; qPCR, quantitative polymerase chain reaction.

inorganic molecules, which, in turn, form stable dispersions in aqueous/parent solutions. ${ }^{35-38}$ In the present work, an inclusion complex of Apa-Cyc was prepared, and this inclusion complex was stable in nature, achieving a stable dispersion of apatinib in an aqueous solution after inclusion of cyclodextrin. Injection of Apa-Cyc achieved a better antitumor effect than oral administration of apatinib. This is important for the treatment of advanced HCC with apatinib, as clinical oral administration of apatinib with daily doses up to 850 mg can represent a great economic burden to patients and have potential side effects that should not be underestimated. Preparation of the cyclodextrin inclusion complex to achieve apatinib injection can improve the efficacy of drugs and relieve the financial burden and the side effects of apatinib experienced by patients.

Moreover, the Apa-Cyc inclusion complex helps to improve the chemical properties of apatinib and enable the preparation of the insoluble apatinib into a stable aqueous solution, which also facilitates the pharmaceutical preparation of apatinib. Application of Apa-Cyc in clinical treatment could also avoid the potential stimulation or toxic/side effects of organic solvents (eg, PEG or Tween) in an apatinib solution (eg, Apa-Sol) when injecting an apatinib solution. Based on this, a temperature-sensitive phase-change hydrogel of apatinib (named Apa-Gel) was prepared with apatinibcyclodextrin and poloxamer 407. Apa-Gel was injected into $\mathrm{HCC}$ tissues in nude mice to examine the long-term antitumor effect. Apa-Gel is a liquid medicament at room temperature, and it can be converted into a hydrogel at body temperature to avoid the quick clearance of drug from tumor tissues being injected into the tissue. HCC cells in the tissue gradually degrade and dissolve the hydrogel (Apa-Gel), releasing the drug from the hydrogel, thus achieving long-term sustaining of apatinib in tumor tissues. In addition, Apa-Gel is 
liquid at room temperature and becomes hydrogel when its temperature is close to body temperature, which not only contributes to more effective drug administration but also offers more choices for transcatheter arterial chemoembolization (TACE) when treating advanced HCC. ${ }^{39,40}$ Current TACE strategy is that chemotherapeutic drugs, such as adriamycin, are directly mixed with the lipiodol and then deposited in the tumor tissues via tumor blood vessels. There are disadvantages to this treatment strategy: 1) adriamycin has excellent water solubility properties, and other drugs, such as lobaplatin, also contain metal ions. However, these drugs are not miscible with lipiodol and cannot exert the best synergistic effect, and 2) embolization agents, such as gel sponges, cannot be loaded with these drugs. In the present work, Apa-Gel, a liquid at room temperature, was found to enter into the tumor tissue and be converted into a gel. Such a hydrogel can not only achieve long-term release of the drug in the tumor tissue but also block the tumor blood vessel and exert an embolism function.

\section{Conclusion}

This study prepared formulations of apatinib to improve the efficiency of apatinib, a newly approved and potentially highly effective molecular targeted agent for treating advanced HCC. A novel slow-releasing system prepared with apatinib-cyclodextrin-poloxamer allows apatinib to be slowly released, facilitates tissue attachment, and thereby preserves the long-acting efficiency of apatinib.

\section{Author contributions}

All authors made substantial contributions to the design and conception, acquisition, analysis, or interpretation of data. All authors took part in either drafting or revising the manuscript. All authors also gave final approval of the version to be published and agree to be accountable for all aspects of the work in ensuring that questions related to the accuracy or integrity of any part of the work are appropriately investigated and resolved.

\section{Disclosure}

The authors report no conflicts of interest in this work.

\section{References}

1. Chow PKH, Gandhi M, Tan SB; Asia-Pacific Hepatocellular Carcinoma Trials Group. SIRveNIB: selective internal radiation therapy versus sorafenib in Asia-Pacific patients with hepatocellular carcinoma. J Clin Oncol. 2018;36:1913-1921.

2. Reiss KA, Yu S, Mamtani R, et al. Starting dose of sorafenib for the treatment of hepatocellular carcinoma: a retrospective, multi-institutional study. J Clin Oncol. 2017;35(31):3575-3581.
3. El-Khoueiry AB, Sangro B, Yau T, et al. Nivolumab in patients with advanced hepatocellular carcinoma (CheckMate 040): an open-label, non-comparative, phase $1 / 2$ dose escalation and expansion trial. Lancet. 2017;389(10088):2492-2502.

4. Feng F, Jiang Q, Jia H, et al. Which is the best combination of TACE and Sorafenib for advanced hepatocellular carcinoma treatment? A systematic review and network meta-analysis. Pharmacol Res. 2018; 135:89-101.

5. Forner A, Reig M, Bruix J. Hepatocellular carcinoma. Lancet. 2018; 391(10127):1301-1314.

6. Kabir TD, Ganda C, Brown RM, et al. A microRNA-7/growth arrest specific 6/TYRO3 axis regulates the growth and invasiveness of sorafenib-resistant cells in human hepatocellular carcinoma. Hepatology. 2018;67(1):216-231.

7. Petrou P. Value-Based pricing and the end of pharmaceutical pricing as we know it? A case study on sorafenib and axitinib. Pharmacol Res. 2017;124:160-163.

8. Tian Y, Liu Z, Zhang L, et al. Apatinib-loaded lipid nanobubbles combined with ultrasound-targeted nanobubble destruction for synergistic treatment of HepG2 cells in vitro. Onco Targets Ther. 2018;11: 4785-4795.

9. Gourley C. Apatinib and etoposide: surprising efficacy of an oral combination. Lancet Oncol. 2018;19(9):1146-1147.

10. Bruix J, Qin S, Merle P, et al. Regorafenib for patients with hepatocellular carcinoma who progressed on sorafenib treatment (RESORCE): a randomised, double-blind, placebo-controlled, phase 3 trial. Lancet. 2017;389(10064):56-66.

11. Raufi A, Tirona MT. Prospect of the use of checkpoint inhibitors in hepatocellular cancer treatments. Cancer Manag Res. 2017;9:19-27.

12. Wang Y, Gou Q, Xu R, Chen X, Zhou Z. Efficacy and safety of sorafenib versus apatinib in the treatment of intermediate and advanced hepatocellular carcinoma: a comparative retrospective study. Onco Targets Ther. 2018;11:3407-3413.

13. Lan CY, Wang Y, Xiong Y, et al. Apatinib combined with oral etoposide in patients with platinum-resistant or platinum-refractory ovarian cancer (AEROC): a phase 2, single-arm, prospective study. Lancet Oncol. 2018;19(9):1239-1246.

14. Giglio V, Viale M, Bertone V, Maric I, Vaccarone R, Vecchio G. Cyclodextrin polymers as nanocarriers for sorafenib. Invest New Drugs. 2018;36(3):370-379.

15. Kim A, Mccully C, Cruz R, et al. The plasma and cerebrospinal fluid pharmacokinetics of sorafenib after intravenous administration in non-human primates. Invest New Drugs. 2012;30(2):524-528.

16. Feng SQ, Wang GJ, Zhang JW, et al. Combined treatment with apatinib and docetaxel in A549 xenograft mice and its cellular pharmacokinetic basis. Acta Pharmacol Sin. 2018;39(10):1670-1680.

17. Feng S, Zhang J, Wang Y, et al. Application of liquid chromatographytandem mass spectrometry to study the effect of docetaxel on pharmacokinetics and tissue distribution of apatinib in mice. J Chromatogr B Analyt Technol Biomed Life Sci. 2018;1083:198-203.

18. Xie H, Tian S, Yu H, et al. A new apatinib microcrystal formulation enhances the effect of radiofrequency ablation treatment on hepatocellular carcinoma. Onco Targets Ther. 2018;11:3257-3265.

19. Shao Z, Li Y, Dai W, et al. ETS-1 induces Sorafenib-resistance in hepatocellular carcinoma cells via regulating transcription factor activity of PXR. Pharmacol Res. 2018;135:188-200.

20. Li J, Zhao J, Wang H, et al. MicroRNA-140-3p enhances the sensitivity of hepatocellular carcinoma cells to sorafenib by targeting pregnenolone X receptor. Onco Targets Ther. 2018;11:5885-5894.

21. Wu M, Zhao G, Zhuang X, et al. Triclosan treatment decreased the antitumor effect of sorafenib on hepatocellular carcinoma cells. Onco Targets Ther. 2018;11:2945-2954.

22. Jia $H$, Yang Q, Wang $T$, et al. Rhamnetin induces sensitization of hepatocellular carcinoma cells to a small molecular kinase inhibitor or chemotherapeutic agents. Biochim Biophys Acta. 2016;1860(7): 1417-1430. 
23. An L, Li DD, Chu HX, et al. Terfenadine combined with epirubicin impedes the chemo-resistant human non-small cell lung cancer both in vitro and in vivo through EMT and Notch reversal. Pharmacol Res. 2017;124:105-115.

24. Feng F, Jiang Q, Cao S, et al. Pregnane X receptor mediates sorafenib resistance in advanced hepatocellular carcinoma. Biochim Biophys Acta Gen Subj. 2018;1862(4):1017-1030.

25. Li L, Liang Y, Kang L, et al. Transcriptional regulation of the Warburg effect in cancer by SIX1. Cancer Cell. 2018;33(3):368-385.

26. Kang J, Kim E, Kim W, et al. Rhamnetin and cirsiliol induce radiosensitization and inhibition of epithelial-mesenchymal transition (EMT) by miR-34a-mediated suppression of Notch-1 expression in non-small cell lung cancer cell lines. J Biol Chem. 2013;288(38):27343-27357.

27. Won JK, Yu SJ, Hwang CY, et al. Protein disulfide isomerase inhibition synergistically enhances the efficacy of sorafenib for hepatocellular carcinoma. Hepatology. 2017;66(3):855-868.

28. Parikh ND, Marshall VD, Singal AG, et al. Survival and cost-effectiveness of sorafenib therapy in advanced hepatocellular carcinoma: An analysis of the SEER-Medicare database. Hepatology. 2017;65(1):122-133.

29. Zhu YJ, Zheng B, Wang HY, Chen L. New knowledge of the mechanisms of sorafenib resistance in liver cancer. Acta Pharmacol Sin. 2017;38(5):614-622.

30. Hou J, Hong Z, Feng F, et al. A novel chemotherapeutic sensitivitytesting system based on collagen gel droplet embedded 3D-culture methods for hepatocellular carcinoma. BMC Cancer. 2017;17(1):729.

31. Polaris Observatory Collaborators. Global prevalence, treatment, and prevention of hepatitis B virus infection in 2016: a modelling study. Lancet Gastroenterol Hepatol. 2018;3(6):383-403.

32. Nayagam S, Thursz M, Sicuri E, et al. Requirements for global elimination of hepatitis B: a modelling study. Lancet Infect Dis. 2016;16(12): 1399-1408
33. Wang FS, Fan JG, Zhang Z, Gao B, Wang HY. The global burden of liver disease: the major impact of China. Hepatology. 2014;60(6): 2099-2108.

34. Zhang S, Wang F, Zhang Z. Current advances in the elimination of hepatitis B in China by 2030. Front Med. 2017;11(4):490-501.

35. Diamantis DA, Ramesova S, Chatzigiannis CM, et al. Exploring the oxidation and iron binding profile of a cyclodextrin encapsulated quercetin complex unveiled a controlled complex dissociation through a chemical stimulus. Biochim Biophys Acta Gen Subj. 2018;1862(9): 1913-1924.

36. de Rossi MC, Wetzler DE, Benseñor L, et al. Mechanical coupling of microtubule-dependent motor teams during peroxisome transport in Drosophila S2 cells. Biochim Biophys Acta Gen Subj. 2017;1861(12): 3178-3189.

37. Martínez-Negro M, Caracciolo G, Palchetti S, et al. Biophysics and protein corona analysis of Janus cyclodextrin-DNA nanocomplexes. Efficient cellular transfection on cancer cells. Biochim Biophys Acta Gen Subj. 2017;1861(7):1737-1749.

38. Costa GA, de Souza SB, da Silva Teixeira LR, et al. Tumor cell cholesterol depletion and V-ATPase inhibition as an inhibitory mechanism to prevent cell migration and invasiveness in melanoma. Biochim Biophys Acta Gen Subj. 2018;1862(3):684-691.

39. European Association for the Study of the Liver; European Organisation for Research and Treatment of Cancer. EASL-EORTC clinical practice guidelines: management of hepatocellular carcinoma. J Hepatol. 2012; 56:908-943.

40. European Association for Study of Liver; European Organisation for Research and Treatment of Cancer. EASL-EORTC clinical practice guidelines: management of hepatocellular carcinoma. Eur J Cancer. 2012;48:599-641. 


\section{Supplementary material}

A

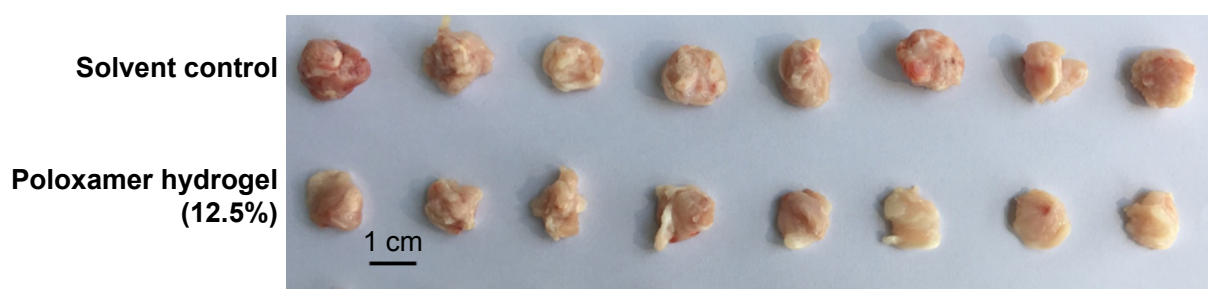

B

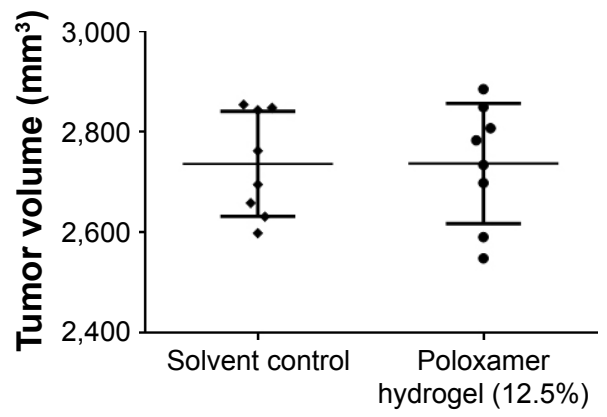

C

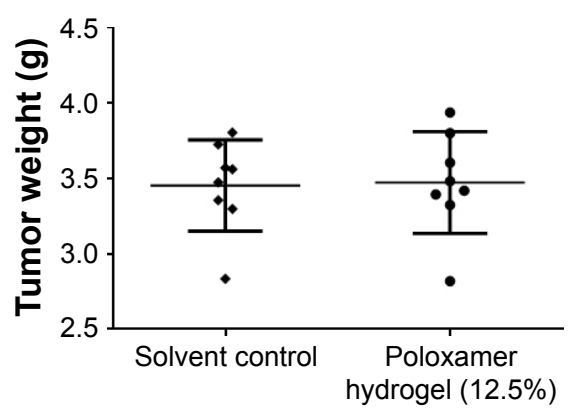

Figure SI Poloxamer 407 hydrogel did not inhibit subcutaneous growth of MHCC97-H in nude mice.

Notes: MHCC97-H cells were injected into nude mice to form subcutaneous tumors. The control group mice received intratumor injection of solvent control. Mice were once administered with $12.5 \%$ concentration of poloxamer 407 hydrogel. The results are shown as (A) photographs of tumors, (B) tumor volumes, and (C) tumor weights.

\section{Publish your work in this journal}

OncoTargets and Therapy is an international, peer-reviewed, open access journal focusing on the pathological basis of all cancers, potential targets for therapy and treatment protocols employed to improve the management of cancer patients. The journal also focuses on the impact of management programs and new therapeutic agents and protocols on patient perspectives such as quality of life, adherence and satisfaction. The manuscript management system is completely online and includes a very quick and fair peer-review system, which is all easy to use. Visit http://www.dovepress.com/testimonials.php to read real quotes from published authors. 